\title{
Virulence Factor Genes and Antimicrobial Susceptibility of Staphylococcus aureus Strains Isolated from Blood and Chronic Wounds
}

\author{
Anna Budzyńska ${ }^{1}$ (D), Krzysztof Skowron ${ }^{1, * \mathbb{D}}$, Agnieszka Kaczmarek ${ }^{1}$, Magdalena Wietlicka-Piszcz ${ }^{2}$ \\ and Eugenia Gospodarek-Komkowska ${ }^{1}$ \\ 1 Department of Microbiology, Ludwik Rydygier Collegium Medicum in Bydgoszcz, \\ Nicolaus Copernicus University in Torun, 9 M. Skłodowska-Curie St., 85-094 Bydgoszcz, Poland; \\ a.budzynska@cm.umk.pl (A.B.); a.kaczmarek@cm.umk.pl (A.K.); gospodareke@cm.umk.pl (E.G.-K.) \\ 2 Department of Theoretical Foundations of Biomedical Sciences and Medical Computer Science, \\ L. Rydygier Collegium Medicum in Bydgoszcz, Nicolaus Copernicus University in Torun, \\ 9 M. Skłodowska-Curie St., 85-094 Bydgoszcz, Poland; mpiszcz@cm.umk.pl \\ * Correspondence: skowron238@wp.pl; Tel.: +48-512-210-245
}

Citation: Budzyńska, A.; Skowron, K.; Kaczmarek, A.; Wietlicka-Piszcz, M.; Gospodarek-Komkowska, E. Virulence Factor Genes and Antimicrobial Susceptibility of Staphylococcus aureus Strains Isolated from Blood and Chronic Wounds. Toxins 2021, 13, 491. https://doi.org/ $10.3390 /$ toxins 13070491

Received: 29 June 2021

Accepted: 12 July 2021

Published: 14 July 2021

Publisher's Note: MDPI stays neutral with regard to jurisdictional claims in published maps and institutional affiliations.

Copyright: (c) 2021 by the authors. Licensee MDPI, Basel, Switzerland. This article is an open access article distributed under the terms and conditions of the Creative Commons Attribution (CC BY) license (https:// creativecommons.org/licenses/by/ $4.0 /)$.

\begin{abstract}
Staphylococcus aureus is one of the predominant bacteria isolated from skin and soft tissue infections and a common cause of bloodstream infections. The aim of this study was to compare the rate of resistance to various antimicrobial agents and virulence patterns in a total of 200 S. aureus strains isolated from patients with bacteremia and chronic wounds. Disk diffusion assay and in the case of vancomycin and teicoplanin-microdilution assay, were performed to study the antimicrobial susceptibility of the isolates. The prevalence of genes encoding six enterotoxins, two exfoliative toxins, the Panton-Valentine leukocidin and the toxic shock syndrome toxin was determined by PCR. Of the 100 blood strains tested, the highest percentage $(85.0 \%, 31.0 \%$, and $29.0 \%)$ were resistant to benzylpenicillin, erythromycin and clindamycin, respectively. Out of the 100 chronic wound strains, the highest percentage $(86.0 \%, 32.0 \%, 31.0 \%, 31.0 \%, 30.0 \%$, and $29.0 \%)$ were confirmed as resistant to benzylpenicillin, tobramycin, amikacin, norfloxacin, erythromycin, and clindamycin, respectively. A significantly higher prevalence of resistance to amikacin, gentamicin, and tobramycin was noted in strains obtained from chronic wounds. Moreover, a significant difference in the distribution of sea and sei genes was found. These genes were detected in $6.0 \%, 46.0 \%$ of blood strains and in $19.0 \%$, and $61.0 \%$ of wound strains, respectively. Our results suggest that $S$. aureus strains obtained from chronic wounds seem to be more often resistant to antibiotics and harbor more virulence genes compared to strains isolated from blood.
\end{abstract}

Keywords: bacteremia; chronic wound; resistance; Staphylococcus aureus; virulence genes

Key Contribution: S. aureus strains obtained from chronic wounds were more often resistant to antibiotics, and harbored more virulence genes compared to strains isolated from blood. A statistically significant difference was observed in the incidence of sea and sei genes, and the percentage of strains resistant to amikacin, gentamicin and tobramycin.

\section{Introduction}

Staphylococcus aureus is a common opportunistic pathogen that causes a variety of infections due to the presence of many colonization factors and virulence factors. It is one of the most frequent causes of skin and soft tissue infections (SSTIs) such as skin abscesses, furuncles, impetigo, and wound infections. Some of them, especially in patients with risk factors (diabetics, patients during immunosuppressive or cancer therapy, patients with indwelling catheters, HIV/AIDS), may progress to severe infections and require hospitalization. S. aureus is also a leading cause of serious infections, such as bacteremia (S. aureus bacteremia, $\mathrm{SAB}$ ) or infective endocarditis, which can have serious consequences 
for the patient. High morbidity and mortality are associated especially with the widespread occurrence of methicillin-resistant $S$. aureus (MRSA) strains. Resistance to all $\beta$-lactams (except for the latest generation of cephalosporins) and other antibiotics commonly used limits therapeutic options for treating staphylococcal infections [1-3].

Among virulence factors produced by this microorganism, the pore-forming toxins (e.g., hemolysins, leukotoxins), enzymes (e.g., nucleases, staphylokinase, coagulases), epidermolytic toxins, and superantigens (SAgs) can be distinguished.

Panton-Valentine leukocidin (PVL) - encoded by two genes, luk-S-PV, and luk-F-PVis an extracellular protein with dermonecrotic and leucocidal functions. It has cytotoxic activity against mammalian neutrophils, monocytes, and macrophages. The toxin can be produced both by community-acquired MRSA (CA-MRSA) as well as communityacquired methicillin-susceptible S. aureus (CA-MSSA) strains. PVL-positive strains usually cause SSTIs, but they are also associated with severe infections, including septic arthritis, bacteremia, necrotizing pneumonia, and purpura fulminans $[4,5]$.

Exfoliative toxins (ETs) are specific serine proteases that recognize and hydrolyze desmosome proteins in the skin and, therefore, play a role in host colonization and the invasion of injured mucosa and skin. ETs are causative agents for localized epidermal infections and generalized disease-staphylococcal scalded skin syndrome (SSSS). Serotypes ETA, ETB, and ETD are also associated with septic shock and may increase the severity of the infection $[6,7]$.

Toxic shock syndrome toxin-1 (TSST-1) and staphylococcal enterotoxins (SEs), with their superantigenic properties, may contribute to the development of serious infections due to the activation of enormous numbers of T lymphocytes. TSST- 1 is a bacterial exotoxin produced by approximately $5-25 \%$ of $S$. aureus strains isolated from samples of different origins $[8,9]$. It is responsible for menstrual and non-menstrual cases of toxic shock syndrome, a severe and potentially fatal disease in humans or for neonatal toxic shock syndrome-like exanthematous disease. SEs are subdivided into classical SEs with emetic activity and SE-like proteins with no or relatively low emetic activity [10]. SEs play an important role in staphylococcal food poisoning, but these virulence factors are associated also with the pathogenesis of several other human diseases, including pneumonia, sepsis-related infections, or toxic shock syndrome. Futhermore, SEB is capable of inhibiting keratinocyte proliferation and migration and may delay wound closure [11,12].

Recent studies have shown that staphylococcal SAgs affect the site of infection to cause tissue pathology and are crucial in the development and progression of sepsis and infective endocarditis [13]. SAgs produced by S. aureus colonizing the wounds may also play a major inhibitory role in the healing of chronic wounds because of the recurrent exposure to those virulence factors [14].

This study aimed to compare drug susceptibility and virulence patterns in S. aureus strains isolated from patients with $\mathrm{SAB}$ or a chronic wound.

\section{Results}

\subsection{Antibiotic Susceptibility Analysis}

All the strains analysed were susceptible to ceftaroline, vancomycin, teicoplanin, tigecycline, linezolid, and rifampicin. The MIC range for the vancomycin was $0.5-1.5 \mu \mathrm{g} \cdot \mathrm{mL}^{-1}$ and for teicoplanin $0.5-1.0 \mu \mathrm{g} \cdot \mathrm{mL}^{-1}$. The resistance to antibiotics was observed more frequently in strains isolated from wounds than in strains isolated from blood (276 (18.4\%) versus $222(14.7 \%))(p=0.007)$. In the two groups, the highest resistance was observed to benzylpenicillin (Table 1). Moreover, in the group of wound strains, high percentages of strains not susceptible to tobramycin (32.0\%), norfloxacin $(31.0 \%)$, amikacin $(31.0 \%)$, erythromycin $(30.0 \%)$, and clindamycin $(29.0 \%)$ were determined, whereas among blood strains, $31.0 \%$ and $29.0 \%$ of strains were resistant to erythromycin and clindamycin, respectively. Only with aminoglycosides were there statistically significant differences; higher prevalence of resistance to these antibiotics was observed in strains isolated from chronic wounds $(p<0.05)$. Of the 200 S. aureus strains, $23(23.0 \%)$ blood strains and 
$21(21.0 \%)$ wound strains were identified as MRSA. An iMLS $\mathrm{B}_{\mathrm{B}}$ and $\mathrm{CMLS}_{\mathrm{B}}$ (constitutive MLS $_{\mathrm{B}}$ resistance) phenotype was observed in $19(19.0 \%)$ and $11(11.0 \%)$ of the blood strains, respectively, and in $14(14.0 \%)$ and $14(14.0 \%)$ of the wound strains, respectively. In the present study, $34(34.0 \%)$ and $33(33.0 \%)$ strains isolated from blood and chronic wounds were multidrug-resistant, of which 23 strains were methicillin-susceptible (Table 2). Only $6(6.0 \%)$ wound strains and $14(14.0 \%)$ blood strains were susceptible to all antibiotics tested. Resistance to one antimicrobial agent was seen in the majority of blood and wound strains (46.0\% and $37.0 \%$, respectively). The most frequent resistance phenotypes besides the $P$ ( $40.5 \%$ of all strains) were P-E-CC (10.3\% of MSSA strains) and P- NOR-AMK-TOB-E-CC (34.1\% of MRSA strains).

Table 1. Comparison of the antimicrobial resistance between wound and blood S. aureus strains.

\begin{tabular}{|c|c|c|c|c|}
\hline Antibiotic & $\begin{array}{c}\text { Total No. of } \\
\text { S. aureus, R (\%) }\end{array}$ & $\begin{array}{l}\text { Chronic Wound } \\
(n=100), \mathrm{R}(\%)\end{array}$ & $\begin{array}{c}\text { Blood }(n=100) \\
\text { R }(\%)\end{array}$ & $p$ Value \\
\hline Benzylpenicillin & $171(85.5)$ & $86(86.0)$ & $85(85.0)$ & 1 \\
\hline Cefoxitin & $44(22.0)$ & $21(21.0)$ & $23(23.0)$ & 0.865 \\
\hline Ceftaroline & 0 & 0 & 0 & 1 \\
\hline Norfloxacin & $54(27.0)$ & $31(31.0)$ & $23(23.0)$ & 0.265 \\
\hline Amikacin & $43(21.5)$ & $31(31.0)$ & $12(12.0)$ & 0.002 \\
\hline Gentamicin & $14(7.0)$ & $13(13.0)$ & $1(1.0)$ & 0.001 \\
\hline Tobramycin & $46(23.0)$ & $32(32.0)$ & $14(14.0)$ & 0.004 \\
\hline Teicoplanin & 0 & 0 & 0 & 1 \\
\hline Vancomycin & 0 & 0 & 0 & 1 \\
\hline Erythromycin & $59(29.5)$ & $30(30.0)$ & $29(29.0)$ & 1 \\
\hline Clindamycin & $60(30.0)$ & $29(29.0)$ & $31(31.0)$ & 0.877 \\
\hline Tigecycline & 0 & 0 & 0 & 1 \\
\hline Linezolid & 0 & 0 & 0 & 1 \\
\hline Rifampicin & 0 & 0 & 0 & 1 \\
\hline $\begin{array}{l}\text { Trimethoprim- } \\
\text { sulfamethoxazole }\end{array}$ & $5(2.5)$ & $3(3.0)$ & $2(2.0)$ & 1 \\
\hline
\end{tabular}

Table 2. Antimicrobial resistance patterns among wound and blood S. aureus strains.

\begin{tabular}{|c|c|c|c|c|}
\hline \multirow{2}{*}{ Resistance Profile } & \multicolumn{2}{|c|}{$\begin{array}{c}\text { Chronic Wound } \\
(n=100)(\%)\end{array}$} & \multicolumn{2}{|c|}{ Blood $(n=100)(\%)$} \\
\hline & MRSA & MSSA & MRSA & MSSA \\
\hline Susceptible to all antibiotics & - & $6(6.0)$ & - & $14(14.0)$ \\
\hline $\mathrm{P}$ & 0 & $35(35.0)$ & 0 & $46(46.0)$ \\
\hline NOR & 0 & $2(2.0)$ & 0 & 0 \\
\hline $\mathrm{P}, \mathrm{NOR}$ & $1(1.0)$ & $5(5.0)$ & $2(2.0)$ & $2(2.0)$ \\
\hline P, AMK & 0 & $1(1.0)$ & 0 & 0 \\
\hline$P, G$ & 0 & $2(2.0)$ & 0 & 0 \\
\hline E, CC & 0 & $3(3.0)$ & 0 & $1(1.0)$ \\
\hline AMK, TOB & 0 & $2(2.0)$ & 0 & 0 \\
\hline $\mathrm{P}, \mathrm{AMK}, \mathrm{TOB}$ & $1(1.0)$ & $5(5.0)$ & $1(1.0)$ & $3(3.0)$ \\
\hline $\mathrm{P}, \mathrm{NOR}, \mathrm{AMK}$ & 0 & $1(1.0)$ & 0 & 0 \\
\hline $\mathrm{P}, \mathrm{NOR}, \mathrm{SXT}$ & 0 & 0 & $1(1.0)$ & 0 \\
\hline $\mathrm{P}, \mathrm{E}, \mathrm{CC}$ & 0 & $6(6.0)$ & $1(1.0)$ & $10(10.0)$ \\
\hline $\mathrm{P}, \mathrm{AMK}, \mathrm{G}, \mathrm{TOB}$ & 0 & $6(6.0)$ & 0 & 0 \\
\hline P, AMK, G, CC & 0 & 0 & $1(1.0)$ & 0 \\
\hline $\mathrm{P}, \mathrm{NOR}, \mathrm{E}, \mathrm{CC}$ & $5(5.0)$ & 0 & $7(7.0)$ & $1(1.0)$ \\
\hline P, NOR, AMK, G, SXT & $1(1.0)$ & 0 & 0 & 0 \\
\hline P, AMK, G, TOB, E & $1(1.0)$ & 0 & 0 & 0 \\
\hline P, NOR, TOB, E, CC & $3(3.0)$ & 0 & $3(3.0)$ & 0 \\
\hline P, NOR, AMK, G, TOB, SXT & 0 & $1(1.0)$ & 0 & 0 \\
\hline P, NOR, AMK, TOB, E, CC & $9(9.0)$ & 0 & $6(6.0)$ & 0 \\
\hline
\end{tabular}


Table 2. Cont.

\begin{tabular}{ccccc}
\hline \multirow{2}{*}{ Resistance Profile } & \multicolumn{2}{c}{$\begin{array}{c}\text { Chronic Wound } \\
(\boldsymbol{n}=\mathbf{1 0 0 )}(\mathbf{\%})\end{array}$} & \multicolumn{2}{c}{ Blood $(\boldsymbol{n = 1 0 0 )} \mathbf{( \% )}$} \\
\cline { 2 - 5 } & MRSA & MSSA & MRSA & MSSA \\
\hline P, NOR, AMK, TOB, CC, SXT & 0 & 0 & $1(1.0)$ & 0 \\
NOR, AMK, G, TOB, E, CC & 0 & $1(1.0)$ & 0 & 0 \\
P, NOR, AMK, G, TOB, E, CC, SXT & 0 & $1(1.0)$ & 0 & 0 \\
\hline
\end{tabular}

P-Benzylpenicillin, NOR-Norfloxacin, AMK-Amikacin, TOB-Tobramycin, E-Erythromycin, CCClindamycin, FOX-Cefoxitin, G-Gentamicin, SXT-Trimethoprim-sulfamethoxazole.

\subsection{Frequency of Virulence Genes}

The frequencies of virulence genes are listed in Table 3. The most prevalent toxinencoding genes detected, regardless of the origin of the $\mathrm{S}$. aureus strains, were sei and seg. About one-fifth of the wound strains had sed or eta genes (20.0\% and $19.0 \%$, respectively). The etb gene was present only in one blood strain. Compared with blood strains, the carriage rates for sea and sei genes in wound strains were significantly higher $(p<0.05)$.

Table 3. Frequencies of virulence genes among wound and blood strains and among MRSA and MSSA strains.

\begin{tabular}{|c|c|c|c|c|c|c|c|}
\hline $\begin{array}{l}\text { Virulence } \\
\text { Genes }\end{array}$ & $\begin{array}{l}\text { Total No. of } \\
\text { S. aureus (\%) }\end{array}$ & $\begin{array}{c}\text { Chronic Wound } \\
(n=100)(\%)\end{array}$ & $\begin{array}{c}\text { Blood } \\
(n=100)(\%)\end{array}$ & $p$ Value & $\begin{array}{c}\text { MRSA } \\
(n=44)(\%)\end{array}$ & $\begin{array}{c}\text { MSSA } \\
(n=156)(\%)\end{array}$ & $p$ Value \\
\hline sea & $25(12.5)$ & $19(19.0)$ & $6(6.0)$ & 0.009 & $2(4.5)$ & $23(14.7)$ & 0.071 \\
\hline seb & $4(2.0)$ & $3(3.0)$ & $1(1.0)$ & 0.621 & $1(2.3)$ & $3(1.9)$ & 0.884 \\
\hline $\mathrm{sec}$ & $15(7.5)$ & $8(8.0)$ & $7(7.0)$ & 1.000 & $5(11.4)$ & $10(6.4)$ & 0.271 \\
\hline sed & $32(16.0)$ & $20(20.0)$ & $12(12.0)$ & 0.176 & $18(40.9)$ & $14(9.0)$ & 0.001 \\
\hline seg & $104(52.0)$ & $59(59.0)$ & $45(45.0)$ & 0.066 & $34(77.3)$ & $70(44.9)$ & 0.001 \\
\hline sei & 107 (53.5) & $61(61.0)$ & $46(46.0)$ & 0.047 & 35 (79.5) & $72(46.2)$ & 0.001 \\
\hline tst & $22(11.0)$ & $13(13.0)$ & $9(9.0)$ & 0.499 & $4(9.1)$ & $18(11.5)$ & 0.647 \\
\hline eta & $27(13.5)$ & $14(14.0)$ & $13(13.0)$ & 1,000 & $2(4.5)$ & $25(16.0)$ & 0.049 \\
\hline$e t b$ & $1(0.5)$ & 0 & $1(1.0)$ & 1,000 & 0 & $1(0.6)$ & 0.594 \\
\hline$l u k-F / S-P V$ & $4(2.0)$ & $3(3.0)$ & $1(1.0)$ & 0.621 & $1(2.3)$ & $3(1.9)$ & 0.884 \\
\hline
\end{tabular}

In the present study, 106 (67.9\%) of the 144 MSSA strains and 40 (90.9\%) of the 44 MRSA strains harbored one or more virulence genes. The genes that encode SEI and SEG were also the most common genes both in MSSA and MRSA strains (Table 3). Furthermore, the virulence gene detected among a large number of MRSA strains included sed (40.9\%), whereas etb was not detected among those strains. Twenty-five (16.0\%) and twenty-three $(14.7 \%)$ MSSA strains harbored eta and sea gene, respectively, compared with two of the 44 MRSA strains. The statistically significant differences between MRSA and MSSA were found in the presence of sed, seg, sei and eta genes $(p<0.05)$.

In the tested populations, 39 virulence genes profiles were observed, including 12 common for both groups, 17 typical only for wound strains, and 10 for blood strains. None of the strains simultaneously harbored all tested genes. Twenty-three (57.5\%) wound strains carried at least three virulence genes, whereas among blood strains this ratio was significantly lower $(22.0 \%)$. Among $100 \mathrm{~S}$. aureus strains obtained from a chronic wound, the most were found to be positive for two ( $25.0 \%$ of strains) and for three ( $25.0 \%$ of strains) virulence genes. In contrast, of all blood strains, $37.5 \%$ did not carry any of the tested genes. The most frequent combination detected among both groups was seg-sei $(15.0 \%$ of the wound strains and $21.0 \%$ of the blood strains). All but $22(78.0 \%)$ of the wound strains and 57 (57.0\%) of the blood strains harbored at least one enterotoxin gene. Different patterns of the presence of toxin encoding genes in wound and blood strains are presented in Table 4. 
Table 4. Distribution of virulence genes in chronic wound and blood S. aureus strains.

\begin{tabular}{cccccc}
\hline Gene Profile & $\begin{array}{c}\text { Chronic } \\
\text { Wound (\%) }\end{array}$ & Blood (\%) & Gene Profile & $\begin{array}{c}\text { Chronic } \\
\text { Wound (\%) }\end{array}$ & Blood (\%) \\
\hline Lack of & $19(19.0)$ & $35(35.0)$ & sed, seg, sei & $7(7.0)$ & $6(6.0)$ \\
tested genes & $6(6)$ & $1(1.0)$ & seg, sei, eta & $7(7.0)$ & $3(3.0)$ \\
sei & $5(5.0)$ & $2(2.0)$ & sec, seg, sie & $4(4.0)$ & $2(2.0)$ \\
seg & $1(1.0)$ & $6(6.0)$ & seg, sei, tst & $1(1.0)$ & $4(4.0)$ \\
eta & $2(2.0)$ & $2(2.0)$ & sea, seg, sei & $2(2.0)$ & $1(1.0)$ \\
tst & $3(3.0)$ & 0 & sei, eta, luk-F/S-PV & $2(2.0)$ & 0 \\
sea & 0 & $3(3.0)$ & sea, eta, etb & 0 & $1(1.0)$ \\
sed & $1(1.0)$ & 0 & seg, sei, luk-F/S-PV & 0 & $1(1.0)$ \\
seb & 0 & $1(1.0)$ & sea, sed, sei & $1(1.0)$ & 0 \\
sec & $15(15.0)$ & $21(21.0)$ & sea, seb, luk-F/S-PV & $1(1.0)$ & 0 \\
seg, sei & $3(3.0)$ & 0 & sec, sed, seg, sei & $1(1.0)$ & $2(2.0)$ \\
sei, eta & $3(3.0)$ & 0 & sea, seg, sei, tst & $3(3.0)$ & 0 \\
sed, seg & 0 & $2(2.0)$ & sea, sed, seg, sei & $2(2.0)$ & 0 \\
sea, eta & 0 & $2(2.0)$ & sea, seb, sed, seg & $1(1.0)$ & 0 \\
sei, tst & $1(1.0)$ & $1(1.0)$ & sed, seg, sei, tst & $1(1.0)$ & 0 \\
sea, seg & 0 & $1(1.0)$ & sec, seg, sei, eta & 0 & $1(1.0)$ \\
sea, sed & 0 & $1(1.0)$ & sec, seg, sei, tst & 0 & $1(1.0)$ \\
seb, sei & $1(1.0)$ & 0 & sea, sed, seg, sei, tst & $2(2.0)$ & 0 \\
sea, sei & $1(1.0)$ & 0 & sec, sed, seg, sei, tst & $2(2.0)$ & 0 \\
seg, eta & $1(1.0)$ & 0 & sea, sec, seg, sei, tst & $1(1.0)$ & 0 \\
sea, tst & & & &
\end{tabular}

\subsection{Relationship between the Resistance to Antibiotics and Presence of Toxin Genes}

To select independent factors associated with the detected resistance to antibiotics, the GLMM has been fitted to the data. The results of the uni- and multivariable models estimation are shown in Table 5. The results of the univariable analysis indicate the possible association between the antimicrobial resistance and the strain origin, as well as the presence of the sed, seg, and sei gene. However, in the multivariable analysis, the presence of the sed and seg gene appeared as the only covariate significantly associated with the antimicrobial resistance. The performed analysis shows that the presence of the sed gene in the examined sample increases the odds of the resistance to antibiotics by over nine times on average.

Table 5. Factors associated with the resistance to antibiotics.

\begin{tabular}{|c|c|c|c|c|c|c|c|c|}
\hline Variable & Estimate & SE & $\begin{array}{c}\text { Unadjusted OR } \\
(95 \% \mathrm{CI})\end{array}$ & $p$ Value & Estimate & SE & $\begin{array}{c}\text { Adjusted OR } \\
(95 \% \mathrm{CI})\end{array}$ & $p$ Value \\
\hline & \multicolumn{4}{|c|}{ Univariable models } & \multicolumn{4}{|c|}{ Multivariable model } \\
\hline $\begin{array}{l}\text { chronic wound } \\
\text { vs. blood }\end{array}$ & 0.729 & 0.337 & $2.07(1.07-4.01)$ & 0.03 & 0.424 & 0.301 & $1.53(0.85-2.75)$ & 0.158 \\
\hline sed & 2.565 & 0.405 & $13(5.87-28.78)$ & $<0.001$ & 2.207 & 0.409 & $9.09(4.08-20.27)$ & $<0.001$ \\
\hline seg & 1.334 & 0.326 & $3.8(2.01-7.19)$ & $<0.001$ & 0.854 & 0.417 & $2.35(1.04-5.32)$ & 0.04 \\
\hline sei & 0.849 & 0.333 & $2.34(1.22-4.48)$ & 0.011 & -0.13 & 0.406 & $0.88(0.4-1.95)$ & 0.749 \\
\hline sea & -0.495 & 0.514 & $0.61(0.22-1.67)$ & 0.336 & & & & \\
\hline
\end{tabular}

SE-Standard Error, OR (95\% CI)—odds ratio with 95\% confidence interval.

\section{Discussion}

S. aureus invades different body sites and causes a wide range of infections from mild skin and soft tissue infections to life-threatening diseases. Bloodstream infections remain especially associated with significant mortality, despite the improvements in the treatment of staphylococcal infections [15]. SAB may be associated with infective endocarditis, osteomyelitis, and other metastatic infections. Chronic wounds, often caused by this pathogen, can also be a source of bloodstream infections. Furthermore, non-healing 
wounds due to bacterial infections and biofilm formation are related to increased health costs [16].

A significant concern for public health are MRSA strains. Although, the decline in the resistance percentage was noted in recent years in some countries (e.g., the United Kingdom, Ireland, Germany, Portugal), MRSA remains an important pathogen involved in community- and health care-associated infections [17]. The frequency of isolation of MRSA strains from chronic wounds is varied and depends not only on the country, but also on the population of wound patients studied. Risk factors for infection with a multidrug resistant microorganism include previous hospitalization or stay in a chronic care center (the possibility of cross-contamination of patients' wounds or through the hands of medical staff), or previous antibiotic therapy. Moreover, chronic wounds are a good environment for the development of many different bacteria, which promotes horizontal gene transfer and selection of resistant strains [18,19]. MRSA bloodstream infection, in turn, is associated with high mortality, especially in intensive care patients. In the presented study, $21.0 \%$ of $S$. aureus isolated from chronic wounds were found to be MRSA, whereas Shettigar et al. [20] identified in diabetic foot ulcer patients an almost three times higher percentage of methicillin-resistant strains. The incidence of methicillin resistance that we have noted among strains isolated from blood was similar $(23.0 \%)$ to that of wound strains. A statistically significant difference was indicated between the two groups of strains in resistance to amikacin $(12.0 \%$ vs. $31.0 \%)$, gentamicin $(1.0 \%$ vs. $13.0 \%)$ and tobramycin (14.0\% vs. $32.0 \%$ ). Moreover, among the strains isolated from blood, there was a lower percentage of strains resistant to norfloxacin, but this difference was not statistically significant. However, a similar percentage of blood $(11.0 \%)$ and wound $(14.0 \%)$ strains had a constitutive mechanism of $\mathrm{MLS}_{\mathrm{B}}$ resistance. Compared to it and compared to strains isolated from blood, the inducible $\mathrm{MLS}_{\mathrm{B}}$ mechanism was slightly more frequently reported in strains derived from chronic wounds (19.0 vs. $14.0 \%)$.

Benzylpenicillin resistance was found in most strains in the present study and the studies by other authors [20-24], regardless of the clinical samples from which they were recovered. Among the remaining antibiotics, the highest percentage of all strains tested showed resistance to clindamycin (30.0\%), erythromycin (29.5\%), and norfloxacin $(27.0 \%)$. Similar findings $(19.8 \%, 28.7 \%$, and $27.7 \%$ ) were reported by Pomorska-Wesołowska et al. [25] in Southern Poland on strains isolated from SAB and pneumonia. Other studies conducted by Wang et al. [22], Yu et al. [21], and Liang et al. [26] indicated that the frequencies of erythromycin and clindamycin resistance among isolates collected from blood were significantly higher and amounted to $65.0 \%, 61.8 \%$ and $46.7 \%$ for the former and $58.3 \%, 48.3 \%$ and $40.0 \%$ for the latter of these antibiotics. The widespread use of some macrolides against infections caused by various bacteria promotes among staphylococci colonizing the human body the selection of strains resistant to these antibiotics. In contrast, clindamycin is an alternative to beta-lactam antibiotics for patients allergic to penicillins and can also be used to treat infections caused by MRSA strains. Therefore, in recent years, an increase in the number of strains resistant to macrolides and lincosamides, in particular, the iMLS $\mathrm{B}$ phenotype, has been observed $[27,28]$.

Varshney et al. [29] reported that among strains derived from wounds, 5.6\% are susceptible to all antibiotics and $40.7 \%$ are susceptible to all antibiotics, except for penicillin. We found similar percentages $(6.0 \%$ and $35.0 \%$, respectively). However, in the abovementioned studies, in the case of strains isolated from blood, these percentages were lower compared to the results of our research $(6.1 \%$ and $23.2 \%$ vs. $14.0 \%$ and $46.0 \%)$.

S. aureus pathogenicity correlates with bacteria's capability to produce and secrete a variety of virulence factors that contribute to colonization, invasion, and damage of the host tissue and bacterial spread [30]. Many virulence factors and biofilm formation are under the control of the accessory gene regulator-quorum sensing system (agr-QS). Toxins or proteases secreted by $S$. aureus have an important role in the ability to cause disease, but may become redundant once a chronic infection is established. Because many virulence factors are targets for the immune system, their downregulation or loss of agr-qs 
prevents further recruitment of phagocytes so is crucial for bacterial survival and long-term persistence in host cells/tissue. Strains isolated from chronic infections may also rewire their metabolism to promote biofilm production or may survive in a metabolically inactive state forming small-colony variants [31-33].

In this study, among all the enterotoxin-encoding genes tested, sei and seg were the most frequent. A combination of those two genes was also found to be the most common. This is in accordance with the previous study $[5,15,21,34-36]$ and related to the close location of both genes on the enterotoxin gene cluster (egc) [37]. A significantly higher percentage of sei, seg and sea was found in chronic wound strains than in blood strains (61.0\%, $59.0 \%$ and $19.0 \%$ vs. $46.0 \%, 45.0 \%$ and $6.0 \%$, respectively). A similar relationship was observed in another study [38], among strains isolated from wounds $(56.3 \%, 56.3 \%$ and $43.8 \%)$ and blood $(41.2 \%, 41.2 \%$ and $35.3 \%)$, whereas Pérez-Montarelo et al. [15] recorded a slightly lower percentage of strains causing SSTI harboring those genes compared to strains causing catheter-related bacteremia $(67.7 \%, 68.2 \%$ and $30.8 \%$ vs. $72.8 \%, 75.6 \%$ and $31.4 \%$, respectively). It is believed that egc superantigenes facilitate the colonization of mucosal surfaces and promote bacterial survival but negatively correlate with the severity of infections $[39,40]$. We also observed a higher rate of sea and sed genes among wound strains, which is in accordance with other data [41]. It is considered that sea and sei may be a biomarker to distinguish colonization and infection of a wound [38]. SEA and SED, with their increased ability to induce local inflammatory responses, in turn, may perform a function in perpetuating chronic non-healing wounds. Moreover, Merriman [11] demonstrated that superantigens can delay wound closure by altering cell proliferation and migration.

In our study, the distribution rate of genes other than seg and sei enterotoxin genes among blood strains was much lower (1.0-12.0\%). These findings are inconsistent with those reported previously, where sea $[15,22,39]$, seb [5,35,42], or sec [35] were also widely present. However, Jarraud et al. [43] suggested that seg-sei gene combination without any of the other SEs, TSST-1 and ETs may also be capable of causing diseases such as toxic shock syndrome or staphylococcal scalded skin syndrome.

Park et al. [36] found eta and etb genes in $2.6 \%$ and $100 \%$ SAB strains, respectively, in a two-year study period, but many studies $[3,24,35,38,44]$ showed a higher distribution of eta compared to etb. This is in accordance with our results, where the eta gene was detected in $13.0-14.0 \%$ of the $S$. aureus strains, whereas only $0-1.0 \%$ strains harbored the etb gene. $\mathrm{Li}$ et al. [35] reported that both genes were more common in SAB isolates compared to SSTI isolates recovered from children. The frequency of occurrence of genes encoding exotoxins, however, varies among blood strains of $S$. aureus and may also be equal to or near zero $[34,42,45,46]$.

The luk-F/S-PV gene is detected more often in SSTI isolates than in SAB isolates $[15,26,32,45-48]$, which confirms our results. The incidence of $l u k-F / S-P V$ gene in this study, however, was not high $(3.0 \%)$, unlike the results of other researchers, in which it reached about $80 \%$ [35,47]. These differences may result from testing only strains derived from chronic wounds compared to tests involving different types of SSTI. In the studies conducted on staphylococci isolated from patients with diabetic foot infections, Viquez-Molina et al. [49] detected the $l u k-F / S-P V$ gene in $6.9 \%$ of strains and, in another study [50], this gene was not found in any of the isolates.

TSST-1 produced by S. aureus has been associated with several acute diseases including toxic shock syndrome, but also with chronic diseases. Our data showed that the tst gene was carried by a relatively low (9.0\%) percentage of blood strains, compared to the results of previous studies in which this percentage usually exceeded $10 \%[3,15,34,36,38,45,50,51]$. Compared with SAB strains, the carriage rate for the tst gene in chronic wound strains was slightly higher $(13.0 \%)$, although the difference was not significant. This is in agreement with the results obtained with strains isolated from DFU and other SSTI $[15,20,26,38]$.

Compared to strains derived from chronic wounds, a high percentage $(35.0 \%)$ of strains isolated from patients with SAB did not have any of the genes tested. A lower 
percentage (25.6\% and $29.4 \%$ ) of S. aureus strains obtained from blood without the virulence genes investigated was found by Becker et al. [34] and Demir et al. [38], respectively. In the present study a considerable variety of virulence profiles was observed among all strains, and only 12 of the 39 profiles coincided in both groups. The possession of single genes was observed in $18.0 \%$ and $15.0 \%$ of wound and blood strains, respectively. A similar result was reported in the study by Demir et al. [38].

We found that SEs genes were more frequent among MRSA than MSSA strains. Other studies also showed a significant association between methicillin resistance and the presence of the majority of SEs genes [5,21,36,42,52]. In our study, among the tested genes encoding enterotoxins tested, only sea was found in more MSSA strains than MRSA. Park et al. [36] found no sea gene in MRSA bacteremia isolates, whereas over $16 \%$ of MSSA strains carried this gene.

Our results support the results of other studies [23,36,50,53], in which a higher rate of tst-carrying isolates was detected among methicillin-susceptible isolates compared to that for MRSA isolates, which indicates a possible, inversely proportional relationship between drug resistance of the strains and their virulence in the occurrence of virulence genes.

To our knowledge, scientists most often analyze the difference in the prevalence of virulence genes in MSSA and MRSA strains, while the relationship between the presence of genes encoding toxins and drug susceptibility is less frequently assessed. No significant difference between the antibiotic resistance of non-enterotoxigenic strains and strains producing SEA, SEB, SEC, and SED from mastitic milk was reported by Suleiman et al. [54]. Corredor Arias et al. [55] drew similar conclusions from research results in which 22 superantigen genes were detected in strains isolated from different clinical samples. Choopani et al. [56] reported a relationship between SEG and SEI production and antibiotic resistance, as well as a correlation between seb gene presence and resistance to antibiotics in MRSA strains isolated from a clinical sample in a hospital in Tehran. In our study, an interesting fact was the detection of antibiotic resistance associated with the sed gene.

The association between the distribution of genes encoding virulence factors and the development of a range of staphylococcal infections is still unknown. Moreover, infections caused by multi-resistant $S$. aureus strains remain a challenge for clinicians due to the limited treatment options in patients with such infections. The present research investigated drug susceptibility and virulence patterns in S. aureus strains isolated from chronic wounds and blood. The limitation of the study was the inability to assess the expression of investigated virulence genes and perform molecular typing of the isolates, which would allow for a better interpretation of our findings. Often, antibiotic susceptibility pattern, virulence factors, and their combinations are associated with particular genetic backgrounds (clones) that carry specific pathogenicity islands or plasmids. Although those limitations exist, our results allow us to suggest that strains obtained from chronic wounds seem to be more often resistant to antibiotics and more virulent compared to strains isolated from blood. We observed a statistically significant difference in the incidence of sea and sei genes, and the percentage of strains resistant to amikacin, gentamicin and tobramycin. Further studies on the pathogenesis of $S$. aureus, including molecular typing, are required to elucidate the importance of various virulence factors in strains from patients with $\mathrm{SAB}$ and chronic non-healing wounds.

\section{Materials and Methods}

\subsection{Bacterial Identification and Antibiotic Susceptibility}

A total of 200 S. aureus strains (non-duplicated) isolated from 2015 to 2017 were analyzed in this study. One hundred strains were obtained from chronic wounds (diabetic foot ulcers and venous leg ulcers), the other 100 strains were isolated in the same period from the blood of patients hospitalized at dr. A. Jurasz University Hospital no. 1, L. Rydygier Collegium Medicum in Bydgoszcz, Nicolaus Copernicus University in Torun. The bacteria were identified using matrix-assisted laser desorption ionisation-time of flight mass spectrometry (MALDI-TOF MS) (Bruker, Bremen, Germany). An antimicrobial susceptibility test was carried out using the disk diffusion method recommended by the European 
Committee on Antimicrobial Susceptibility Testing (EUCAST) [57]. The following drugs were tested: benzylpenicillin (1 unit) (P), cefoxitin (30 $\mu \mathrm{g})$ (FOX), ceftaroline $(5 \mu \mathrm{g})(\mathrm{CPT})$, norfloxacin $(10 \mu \mathrm{g})(\mathrm{NOR})$, amikacin $(30 \mu \mathrm{g})(\mathrm{AMK})$, gentamicin $(10 \mu \mathrm{g})(\mathrm{G})$, tobramycin $(10 \mu \mathrm{g})(\mathrm{TOB})$, erythromycin $(15 \mu \mathrm{g})(\mathrm{E})$, clindamycin $(2 \mu \mathrm{g})(\mathrm{CC})$, tigecycline $(15 \mu \mathrm{g})$ (TGC), linezolid $(10 \mu \mathrm{g})(\mathrm{LZD})$, rifampicin $(5 \mu \mathrm{g})(\mathrm{RF})$ and trimethoprim-sulfamethoxazole $(25 \mu \mathrm{g})(\mathrm{SXT})$. Inducible macrolide, lincosamide and streptogramin B (iMLS $\mathrm{B}$ ) resistance was demonstrated by the D-zone test. The minimum inhibitory concentration (MIC) of vancomycin and teicoplanin was determined by microdilutions in Mueller-Hinton broth. Isolates which showed resistance to non-susceptibility to at least one agent in three or more antimicrobial categories were classified as multidrug-resistant.

\subsection{Toxin Genes Detection}

Bacterial DNA was isolated with the Genomic Mini purification kit (A\&A Biotechnology, Gdańsk, Poland) according to the manufacturer's instruction. DNA extracts were used as a template for amplification. The following virulence genes were detected: the staphylococcal enterotoxin genes (sea, seb, sec, sed, seg, sei), the exfoliative toxin genes (eta, etb), the PVL genes $(l u k-F / S-P V)$, and the toxic shock syndrome toxin gene (tst). The presence of those genes was determined via PCR using oligonucleotide primers [43,58], listed in Table 6. Five monoplex PCR and two multiplex PCR assays, to detect simultaneously (1) sec and $t s t$, (2) seb, eta, and $e t b$, were designed, PCR amplifications were performed using the Mastercycler pro thermal cycler (Eppendorf, Stevenage, UK). The PCR mixture contained $1 \mu \mathrm{L}$ DNA template, $0.8 \mu \mathrm{M}$ (seb, sei, eta, etb) $/ 1 \mu \mathrm{M}$ (other genes) of primers (Laboratory of DNA Sequencing and Oligonucleotide Synthesis, IBB Polish Academy of Sciences), $1 \times$ PCR buffer, $1.5 \mathrm{mM} \mathrm{MgCl} 2,200 \mu \mathrm{M}$ dNTP mix (Promega, Madison, WI, USA) and $1 \mathrm{U}$ (sea, sed, seg, sei, luk-F/S-PV) / $2 \mathrm{U}$ (other genes) of GoTaq polymerase (Promega, Madison, WI, USA). Amplification of genes was performed using the following conditions: initial denaturation at $94{ }^{\circ} \mathrm{C}$ for $3 \mathrm{~min}$ followed by 30 (sea, seg, sei, luk-F/S-PV)/ 35 (other genes) cycles of denaturation at $94{ }^{\circ} \mathrm{C}$ for 1 (seb, sec, eta, etb, tst, luk-F/S-PV) / 2 min (other genes), annealing (Table 6) and extension at $68{ }^{\circ} \mathrm{C}\left(\mathrm{seb}\right.$, sec, eta, etb, tst) $/ 72{ }^{\circ} \mathrm{C}$ for $1 \mathrm{~min}$. A 7 min elongation step at $72{ }^{\circ} \mathrm{C}$ was included at the end of the final cycle. S. aureus isolates harboring virulence genes obtained from the National Reference Centre for Staphylococci (Lyon, France) were used as the positive control strains for detecting virulence genes. Negative control was also included in each PCR run. The PCR products were separated by electrophoresis in a $1.5 \%$ agarose gel with SimplySafe (EURx, Gdańsk, Poland) and visualized in a UV transilluminator. GeneRulerTM100 bp DNA Ladder (Fermentas, Waltham, MA, USA) was used as a molecular weight marker.

Table 6. Oligonucleotide primers used for amplification.

\begin{tabular}{|c|c|c|c|c|}
\hline Target & Primer Sequence $\left(5^{\prime} \rightarrow 3^{\prime}\right)$ & Product Size (bp) & Annealing Temp. $\left({ }^{\circ} \mathrm{C}\right)$ & Reference \\
\hline \multirow[t]{2}{*}{ sea } & GAAAAAAGTCTGAATTGCAGGGAACA & 560 & 55 & [58] \\
\hline & CAAATAAATCGTAATTAACCGAAGGTTC & & & \\
\hline seb & $\begin{array}{l}\text { ATTCTATTAAGGACACTAAGTTAGGGA } \\
\text { ATCCCGTTTCATAAGGCGAGT }\end{array}$ & 404 & 57 & [58] \\
\hline \multirow[t]{2}{*}{$\sec$} & GTAAAGTTACAGGTGGCAAAACTTG & 297 & 56 & [58] \\
\hline & CATATCATACCAAAAAGTATTGCCGT & & & \\
\hline sed & $\begin{array}{l}\text { GAATTAAGTAGTACCGCGCTAAATAATATG } \\
\text { GCTGTATTTTTCCTCCGAGAGT }\end{array}$ & 492 & 55 & [58] \\
\hline seg & $\begin{array}{c}\text { AATTATGTGAATGCTCAACCCGATC } \\
\text { AAACTTATATGGAACAAAAGGTACTAGTTC }\end{array}$ & 642 & 55 & [43] \\
\hline sei & $\begin{array}{l}\text { CTCAAGGTGATATTGGTGTAGG } \\
\text { AAAAAACTTACAGGCAGTCCATCTC }\end{array}$ & 576 & 55 & [43] \\
\hline eta & $\begin{array}{c}\text { ACTGTAGGAGCTAGTGCATTTGT } \\
\text { TGGATACTTTTGTCTATCTTTTTCATCAAC }\end{array}$ & 190 & 57 & [58] \\
\hline$e t b$ & $\begin{array}{l}\text { CAGATAAAGAGCTTTATACACACATTAC } \\
\text { AGTGAACTTATCTTTCTATTGAAAAACACTA }\end{array}$ & 612 & 57 & [58] \\
\hline$l u k-F / S-P V$ & $\begin{array}{l}\text { ATCATTAGGTAAAATGTCTGGACATGATCCA } \\
\text { GCATCAASTGTATTGGATAGCAAAAGC }\end{array}$ & 433 & 50 & [58] \\
\hline tst & $\begin{array}{l}\text { TTCACTATTTGTAAAAGTGTCAGACCCACT } \\
\text { TACTAATGAATTTTTTTATCGTAAGCCCTT }\end{array}$ & 180 & 56 & [58] \\
\hline
\end{tabular}




\subsection{Statistical Analysis}

The summary statistics for categorical variables are presented as absolute and relative frequencies. The differences in categorical variables were tested using chi-square or Fisher's exact test for independence. To study the dependence between the resistance to antibiotics and the presence of virulence genes and the sample origin (wound and blood), a generalized linear mixed effects model (GLMM) with a binomial distribution and logit link function has been applied. GLMM is a class of models that enable the modelling of clustered non-normal data of many kinds of response variables. The virulence genes and the origin of the S. aureus strain (blood or wound) have been included in the model as covariates and the antimicrobial resistance as the dependent variable. The antibiotics and the strains' identifiers were included as random effects terms. First, the associations between the antimicrobial resistance and the presence of virulence genes and the $S$. aureus origin have been modelled for each covariate separately (univariable models). Subsequently, the model with multiple covariates was created (multivariable model). Model estimates are reported as odds ratios (ORs).

The results were considered statistically significant when the $p$-value was less than 0.05 . The statistical analysis was performed with the use of the R software (package lme4) [59].

Author Contributions: Conceptualization, A.B. and K.S.; methodology, A.B. and A.K.; validation, A.B. and A.K.; formal analysis, K.S. and M.W.-P.; investigation, A.B. and A.K.; resources, E.G.-K.; data curation, A.B.; writing—original draft preparation, A.B.; writing—review and editing, K.S. and E.G.-K.; visualization, A.B.; supervision, K.S. and E.G.-K.; project administration, A.B.; funding acquisition, E.G.-K. All authors have read and agreed to the published version of the manuscript.

Funding: This research was funded by the NICOLAUS COPERNICUS UNIVERSITY with funds from the maintenance of the research potential of the Department of Microbiology (PDB WF 839, PDB WF 537).

Institutional Review Board Statement: Not applicable.

Informed Consent Statement: Not applicable.

Data Availability Statement: No new data were created or analyzed in this study. Data sharing is not applicable to this article.

Acknowledgments: We are grateful to Michele Bes (Centre National de Référence des Staphylocoques, Institut des Agent infectieux, Hospices Civils de Lyon, Lyon, France) for the S. aureus strains used as positive control for detecting virulence genes.

Conflicts of Interest: The authors declare no conflict of interest.

\section{References}

1. Song, Y.; Du, X.; Li, T.; Zhu, Y.; Li, M. Phenotypic and molecular characterization of Staphylococcus aureus recovered from different clinical specimens of inpatients at a teaching hospital in Shanghai between 2005 and 2010. J. Med. Microbiol. 2013, 62, 274-282. [CrossRef]

2. Grumann, D.; Nübel, U.; Bröker, B.M. Staphylococcus aureus toxins-Their functions and genetics. Infect. Genet. Evol. 2014, 21, 583-592. [CrossRef]

3. Gallardo-García, M.M.; Sánchez-Espín, G.; Ivanova-Georgieva, R.; Ruíz-Morales, J.; Rodríguez-Bailón, I.; Viñuela González, V.; García-López, M.V. Relationship between pathogenic, clinical, and virulence factors of Staphylococcus aureus in infective endocarditis versus uncomplicated bacteremia: A case-control study. Eur. J. Clin. Microbiol. Infect. Dis. 2016, 35, 821-828. [CrossRef]

4. Lina, G.; Piémont, Y.; Godail-Gamot, F.; Bes, M.; Peter, M.O.; Gauduchon, V.; Vandenesch, F.; Etienne, J. Involvement of PantonValentine leukocidin-producing Staphylococcus aureus in primary skin infections and pneumonia. Clin. Infect. Dis. 1999, 29, 1128-1132. [CrossRef]

5. He, C.; Xu, S.; Zhao, H.; Hu, F.; Xu, X.; Jin, S.; Yang, H.; Gong, F.; Liu, Q. Leukotoxin and pyrogenic toxin Superantigen gene backgrounds in bloodstream and wound Staphylococcus aureus isolates from eastern region of China. BMC Infect. Dis. 2018, 18, 395. [CrossRef]

6. Dinges, M.M.; Orwin, P.M.; Schlievert, P.M. Exotoxins of Staphylococcus aureus. Clin. Microbiol. Rev. 2000, 13, 16-34. [CrossRef] 
7. Kong, C.; Neoh, H.M.; Nathan, S. Targeting Staphylococcus aureus Toxins: A Potential form of Anti-Virulence Therapy. Toxins 2016, 8, 72. [CrossRef]

8. El-Ghodban, A.; Ghenghesh, K.S.; Márialigeti, K.; Esahli, H.; Tawil, A. PCR detection of toxic shock syndrome toxin of Staphylococcus aureus from Tripoli, Libya. J. Med. Microbiol. 2006, 55, 179-182. [CrossRef]

9. Hakimi Alni, R.; Mohammadzadeh, A.; Mahmoodi, P.; Alikhani Avicenna, M.Y. Detection of toxic shock syndrome toxin (tsst) gene among Staphylococcus aureus isolated from patients and healthy carriers. J. Clin. Microb. Infec. 2018, 5, 14249. [CrossRef]

10. Zhao, Y.; Tang, J. Staphylococcal enterotoxin M causes intestine dysfunction via activating inflammation. J. Food. Saf. 2018, 38, 12465. [CrossRef]

11. Merriman, J.A. Secreted Staphylococcus aureus Virulence Factors and Their Role in Chronic Wound Development and Persistence. Ph.D. Thesis, University of Iowa, Iowa City, IA, USA, 2015. [CrossRef]

12. Fisher, E.L.; Otto, M.; Cheung, G.Y.C. Basis of Virulence in Enterotoxin-Mediated Staphylococcal Food Poisoning. Front. Microbiol. 2018, 9, 436. [CrossRef]

13. Kulhankova, K.; Kinney, K.J.; Stach, J.M.; Gourronc, F.A.; Grumbach, I.M.; Klingelhutz, A.J.; Salgado-Pabón, W. The Superantigen Toxic Shock Syndrome Toxin 1 Alters Human Aortic Endothelial Cell Function. Infect. Immun. 2018, 86. [CrossRef]

14. Kim, C.K.; Karau, M.J.; Greenwood-Quaintance, K.E.; Tilahun, A.Y.; Krogman, A.; David, C.S.; Pritt, B.S.; Patel, R.; Rajagopalan, G. Superantigen-Producing Staphylococcus aureus Elicits Systemic Immune Activation in a Murine Wound Colonization Model. Toxins 2015, 7, 5308-5319. [CrossRef] [PubMed]

15. Pérez-Montarelo, D.; Viedma, E.; Larrosa, N.; Gómez-González, C.; Ruiz de Gopegui, E.; Muñoz-Gallego, I.; San Juan, R.; Fernández-Hidalgo, N.; Almirante, B.; Chaves, F. Molecular Epidemiology of. Front. Microbiol. 2018, 9, 2210. [CrossRef]

16. Gupta, P.; Singh, H.S.; Shukla, V.K.; Nath, G.; Bhartiya, S.K. Bacteriophage Therapy of Chronic Nonhealing Wound: Clinical Study. Int. J. Low. Extrem. Wounds 2019, 18, 171-175. [CrossRef]

17. Surveillance Report. Surveillance of Antimicrobial Resistance in Europe 2018. Available online: https://www.ecdc.europa.eu/ en/publications-data/surveillance-antimicrobial-resistance-europe-2018 (accessed on 14 June 2020).

18. Day, M.R.; Armstrong, D.G. Factors associated with methicillin resistance in diabetic foot infections. J. Foot Ankle Surg. 1997, 36, 322-325. [CrossRef]

19. Ertugrul, B.M.; Oncul, O.; Tulek, N.; Willke, A.; Sacar, S.; Tunccan, O.G.; Yilmaz, E.; Kaya, O.; Ozturk, B.; Turhan, O.; et al. A prospective, multi-center study: Factors related to the management of diabetic foot infections. Eur. J. Clin. Microbiol. Infect. Dis. 2012, 31, 2345-2352. [CrossRef] [PubMed]

20. Shettigar, K.; Jain, S.; Bhat, D.V.; Acharya, R.; Ramachandra, L.; Satyamoorthy, K.; Murali, T.S. Virulence determinants in clinical Staphylococcus aureus from monomicrobial and polymicrobial infections of diabetic foot ulcers. J. Med. Microbiol. 2016, 65, 1392-1404. [CrossRef] [PubMed]

21. Yu, F.; Li, T.; Huang, X.; Xie, J.; Xu, Y.; Tu, J.; Qin, Z.; Parsons, C.; Wang, J.; Hu, L.; et al. Virulence gene profiling and molecular characterization of hospital-acquired Staphylococcus aureus isolates associated with bloodstream infection. Diagn. Microbiol. Infect. Dis. 2012, 74, 363-368. [CrossRef]

22. Wang, L.X.; Hu, Z.D.; Hu, Y.M.; Tian, B.; Li, J.; Wang, F.X.; Yang, H.; Xu, H.R.; Li, Y.C. Molecular analysis and frequency of Staphylococcus aureus virulence genes isolated from bloodstream infections in a teaching hospital in Tianjin, China. Genet. Mol. Res. 2013, 12, 646-654. [CrossRef] [PubMed]

23. Imani Fooladi, A.A.; Ashrafi, E.; Tazandareh, S.G.; Koosha, R.Z.; Rad, H.S.; Amin, M.; Soori, M.; Larki, R.A.; Choopani, A.; Hosseini, H.M. The distribution of pathogenic and toxigenic genes among MRSA and MSSA clinical isolates. Microb. Pathog. 2015, 81, 60-66. [CrossRef]

24. Wang, X.; Shen, Y.; Huang, W.; Zhou, Y. Characterisation of community-acquired. Epidemiol. Infect. 2019, 147, e323. [CrossRef]

25. Pomorska-Wesołowska, M.; Chmielarczyk, A.; Chlebowicz, M.; Ziółkowski, G.; Szczypta, A.; Natkaniec, J.; Romaniszyn, D.; Pobiega, M.; Dzikowska, M.; Krawczyk, L.; et al. Virulence and antimicrobial resistance of Staphylococcus aureus isolated from bloodstream infections and pneumonia in Southern Poland. J. Glob. Antimicrob. Resist. 2017, 11, 100-104. [CrossRef] [PubMed]

26. Liang, Y.; Tu, C.; Tan, C.; El-Sayed Ahmed, M.A.E.; Dai, M.; Xia, Y.; Liu, Y.; Zhong, L.L.; Shen, C.; Chen, G.; et al. Antimicrobial resistance, virulence genes profiling and molecular relatedness of methicillin-resistant. Infect. Drug. Resist. 2019, 12, 447-459. [CrossRef] [PubMed]

27. Adhikari, R.P.; Shrestha, S.; Barakoti, A.; Amatya, R. Inducible clindamycin and methicillin resistant Staphylococcus aureus in a tertiary care hospital, Kathmandu, Nepal. BMC Infect. Dis. 2017, 17, 483. [CrossRef]

28. Razeghi, M.; Saffarian, P.; Goudarzi, M. Incidence of inducible clindamycin resistance and antibacterial resistance genes variability in clinical Staphylococcus aureus strains: A two-year multicenter study in Tehran, Iran. Gene Rep. 2019, 16, 100411. [CrossRef]

29. Varshney, A.K.; Mediavilla, J.R.; Robiou, N.; Guh, A.; Wang, X.; Gialanella, P.; Levi, M.H.; Kreiswirth, B.N.; Fries, B.C. Diverse enterotoxin gene profiles among clonal complexes of Staphylococcus aureus isolates from the Bronx, New York. Appl. Environ. Microbiol. 2009, 75, 6839-6849. [CrossRef]

30. Vitale, M.; Galluzzo, P.; Buffa, P.G.; Carlino, E.; Spezia, O.; Alduina, R. Comparison of Antibiotic Resistance Profile and Biofilm Production of. Antibiotics 2019, 8, 97. [CrossRef]

31. Prince, A.; Wong Fok Lung, T. Consequences of metabolic interactions during Staphylococcus aureus infection. Toxins 2020, 9 , 581. [CrossRef] 
32. Kim, M.K. Staphylococcus aureus toxins: From their pathogenic roles to anti-virulence therapy using natural products. Biotechnol. Bioproc. E 2019, 24, 424-435. [CrossRef]

33. Tuchscherr, L.; Löffler, B.; Proctor, R.A. Persistence of Staphylococcus aureus: Multiple metabolic pathways impact the expression of virulence factors in small-colony variants (SCVs). Front. Microbiol. 2020, 11, 1028. [CrossRef]

34. Becker, K.; Friedrich, A.W.; Lubritz, G.; Weilert, M.; Peters, G.; Von Eiff, C. Prevalence of genes encoding pyrogenic toxin superantigens and exfoliative toxins among strains of Staphylococcus aureus isolated from blood and nasal specimens. J. Clin. Microbiol. 2003, 41, 1434-1439. [CrossRef]

35. Li, X.; Fang, F.; Zhao, J.; Lou, N.; Li, C.; Huang, T.; Li, Y. Molecular characteristics and virulence gene profiles of Staphylococcus aureus causing bloodstream infection. Braz. J. Infect. Dis. 2018, 22, 487-494. [CrossRef]

36. Park, K.H.; Greenwood-Quaintance, K.E.; Cunningham, S.A.; Rajagopalan, G.; Chia, N.; Jeraldo, P.R.; Mandrekar, J.; Patel, R. Lack of correlation of virulence gene profiles of Staphylococcus aureus bacteremia isolates with mortality. Microb. Pathog. 2019, 133, 103543. [CrossRef]

37. Monday, S.R.; Bohach, G.A. Genes encoding staphylococcal enterotoxins G and I are linked and separated by DNA related to other staphylococcal enterotoxins. J. Nat. Toxins 2001, 10, 1-8.

38. Demir, C.; Aslantaş, Ö.; Duran, N.; Ocak, S.; Özer, B. Investigation of toxin genes in Staphylococcus aureus strains isolated in Mustafa Kemal University Hospital. Turk. J. Med. Sci. 2011, 41, 343-352. [CrossRef]

39. Ferry, T.; Thomas, D.; Genestier, A.L.; Bes, M.; Lina, G.; Vandenesch, F.; Etienne, J. Comparative prevalence of superantigen genes in Staphylococcus aureus isolates causing sepsis with and without septic shock. Clin. Infect. Dis. 2005, 41, 771-777. [CrossRef]

40. Nowrouzian, F.L.; Ali, A.; Badiou, C.; Dauwalder, O.; Lina, G.; Josefsson, E. Impacts of enterotoxin gene cluster-encoded superantigens on local and systemic experimental Staphylococcus aureus infections. Eur. J. Clin. Microbiol. Infect. Dis. 2015, 34, 1443-1449. [CrossRef] [PubMed]

41. Dunyach-Remy, C.; Ngba Essebe, C.; Sotto, A.; Lavigne, J.P. Staphylococcus aureus Toxins and Diabetic Foot Ulcers: Role in Pathogenesis and Interest in Diagnosis. Toxins 2016, 8, 209. [CrossRef]

42. Horváth, A.; Dobay, O.; Sahin-Tóth, J.; Juhász, E.; Pongrácz, J.; Iván, M.; Fazakas, E.; Kristóf, K. Characterisation of antibiotic resistance, virulence, clonality and mortality in MRSA and MSSA bloodstream infections at a tertiary-level hospital in Hungary: A 6-year retrospective study. Ann. Clin. Microbiol. Antimicrob. 2020, 19, 17. [CrossRef] [PubMed]

43. Jarraud, S.; Cozon, G.; Vandenesch, F.; Bes, M.; Etienne, J.; Lina, G. Involvement of enterotoxins G and I in staphylococcal toxic shock syndrome and staphylococcal scarlet fever. J. Clin. Microbiol. 1999, 37, 2446-2449. [CrossRef]

44. Nasirian, S.; Saadatmand, S.; Goudarzi, H.; Goudarzi, M.; Azimi, H. Molecular investigation of methicillin-resistant Staphylococcus aureus strains recovered from the intensive care unit (ICU) based on toxin, adhesion genes and agr locus type analysis. Arch. Clin. Infect. Dis. 2018, 13, e14495. [CrossRef]

45. Rasmussen, G.; Monecke, S.; Ehricht, R.; Söderquist, B. Prevalence of clonal complexes and virulence genes among commensal and invasive Staphylococcus aureus isolates in Sweden. PLoS ONE 2013, 8, e77477. [CrossRef]

46. Maeda, M.; Shoji, H.; Shirakura, T.; Takuma, T.; Ugajin, K.; Fukuchi, K.; Niki, Y.; Ishino, K. Analysis of Staphylococcal Toxins and Clinical Outcomes of Methicillin-Resistant Staphylococcus aureus Bacteremia. Biol. Pharm. Bull. 2016, 39, 1195-1200. [CrossRef]

47. Al Fouzan, W.; Al-Haddad, A.; Udo, E.; Mathew, B.; Dhar, R. Frequency and clinical association of Panton-Valentine leukocidinpositive Staphylococcus aureus isolates: A study from Kuwait. Med. Princ. Pract. 2013, 22, 245-249. [CrossRef] [PubMed]

48. Verdú-Expósito, C.; Romanyk, J.; Cuadros-González, J.; TesfaMariam, A.; Copa-Patiño, J.L.; Pérez-Serrano, J.; Soliveri, J. Study of susceptibility to antibiotics and molecular characterization of high virulence Staphylococcus aureus strains isolated from a rural hospital in Ethiopia. PLoS ONE 2020, 15, e0230031. [CrossRef] [PubMed]

49. Víquez-Molina, G.; Aragón-Sánchez, J.; Pérez-Corrales, C.; Murillo-Vargas, C.; López-Valverde, M.E.; Lipsky, B.A. Virulence Factor Genes in Staphylococcus aureus Isolated From Diabetic Foot Soft Tissue and Bone Infections. Int. J. Low. Extrem. Wounds 2018, 17, 36-41. [CrossRef]

50. Mottola, C.; Semedo-Lemsaddek, T.; Mendes, J.J.; Melo-Cristino, J.; Tavares, L.; Cavaco-Silva, P.; Oliveira, M. Molecular typing, virulence traits and antimicrobial resistance of diabetic foot staphylococci. J. Biomed. Sci. 2016, 23, 33. [CrossRef] [PubMed]

51. Luxner, J.; Zarfel, G.; Johler, S.; Feierl, G.; Leitner, E.; Hoenigl, M.; Grisold, A.J. Genetic characterization of Staphylococcus aureus isolates causing bloodstream infections in Austria. Diagn. Microbiol. Infect. Dis. 2014, 78, 153-156. [CrossRef]

52. Gergova, R.T.; Tsitou, V.S.; Gergova, I.I.; Muhtarova, A.A.; Mitov, I.G. Correlation of methicillin resistance and virulence genes of Staphylococcus aureus with infection types and mode of acquisition in Sofia, Bulgaria. Afr. J. Clin. Exper. Microbiol. 2019, 20, 280-288. [CrossRef]

53. Talha, M.H.; Khazaal, S.S.; Al Hadraawy, M.K.; Mostafavi, S.K.S. Screening of antibiotic resistance genes and virulence determinants of Staphylococcus aureus from skin infections. Meta Gene 2020, 24, 100682. [CrossRef]

54. Suleiman, A.; Umoh, V.; Kwaga, J.; Shaibu, S. Enterotoxigenicity and antibiotic resistance of Staphylococcus aureus isolated from sub-clinical bovine mastitis milk in plateau state, Nigeria. Res. J. Microbiol. 2013, 8, 101-107. [CrossRef]

55. Corredor Arias, L.F.; Luligo Espinal, J.S.; Moncayo Ortiz, J.I.; Santacruz Ibarra, J.J.; Álvarez Aldana, A. Relationship between super antigenicity, antimicrobial resistance and origin of Staphylococcus aureus isolated. Colomb. Med. 2016, 47, 15-20.

56. Choopani, A.; Heiat, M.; Amini, E.; Golpuch, M.; Aghamollaei, H. The relationship between the presence of enterotoxin type B gene and antibiotic resistance in Staphylococcus aureus. J. Appl. Biotech. Rep. 2015, 2, 203-206. 
57. The European Committee on Antimicrobial Susceptibility Testing. Breakpoint Tables for Interpretation of MICs and Zone Diameters. Version 9.0. 2019. Available online: http:/ / www.eucast.org (accessed on 22 September 2019).

58. Jarraud, S.; Mougel, C.; Thioulouse, J.; Lina, G.; Meugnier, H.; Forey, F.; Nesme, X.; Etienne, J.; Vandenesch, F. Relationships between Staphylococcus aureus genetic background, virulence factors, agr groups (alleles), and human disease. Infect. Immun. 2002, 70, 631-641. [CrossRef] [PubMed]

59. Bates, D.; Mächler, M.; Bolker, B.; Walker, S. Fitting Linear Mixed-Effects Models using lme4. J. Stat. Softw. 2015, 67, 1-48. [CrossRef] 